\title{
High transparency and conductivity of heavily In-doped ZnO thin films deposited by dip-coating method
}

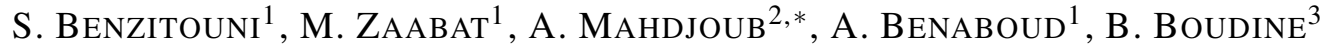 \\ ${ }^{1}$ Laboratoire des Composants Actifs et Matériaux (LCAM), Université Larbi Ben M'Hidi, Oum el Bouaghi 04000, Algieria \\ ${ }^{2}$ Laboratoire des Matériaux et Structures des Systèmes Electromécaniques et leur Fiabilité (LMSSEF), \\ Université Larbi Ben M’Hidi, Oum el Bouaghi 04000, Algieria \\ ${ }^{3}$ Laboratoire de Cristallographie, Université de Constantine 1, Constantine 25000, Algieria
}

\begin{abstract}
Heavily In doped zinc oxide (IZO) thin films were deposited on glass substrates by dip-coating method with different concentrations of indium. The effect of heavy In doping on the structural, morphological, optical and electrical properties of $\mathrm{ZnO}$ was discussed on the basis of XRD, AFM, UV-Vis spectra and Hall effect measurements. The diffraction patterns of all deposited films were indexed to the $\mathrm{ZnO}$ wurtzite structure. However, high In doping damaged the films crystallinity. The highest optical transmittance observed in the visible region $(>93 \%)$ exceeded that of ITO: the absolute rival of the most commercial TCOs. The grain size significantly decreased from $140 \mathrm{~nm}$ for undoped $\mathrm{ZnO}$ to $17.1 \mathrm{~nm}$ for IZO with the greatest In ratio. The roughness decreased with increasing In atomic ratio, indicating an improvement in the surface quality. Among all synthesized films, the sample obtained with 11 at.\% indium showed the best TCO properties: the highest transmittance (93.5\%) and the lowest resistivity $(0.41 \Omega \mathrm{cm})$ with a carrier concentration of $2.4 \times 10^{17} \mathrm{~cm}^{-3}$. These results could be a promising solution for possible photonic and optoelectronic applications.
\end{abstract}

Keywords: ZnO:In; dip coating; resistivity; transparency; crystallinity

\section{Introduction}

Many recent works have been devoted to the one-dimensional growth of $\mathrm{ZnO}$ nanostructures such as nanorods and nanotubes, considered as the most promising candidates for future nanodevices, such as light-emitting diodes [1,2], dye sensitized solar cells (DSSC) [3, 4] and gas sensors [5]. These nanostructures can also be used as photocatalysts [6] and in biomedical applications [7]. $\mathrm{ZnO}$ - a low-toxic and available at low cost material [8] - attracts attention because of its specific properties such as a low temperature process, excellent piezoelectricity and pyroelectricity $[9,10]$. A direct band gap about $3.3 \mathrm{eV}$ and a large exciton binding energy ( $60 \mathrm{meV})$ at room temperature facilitate its application in the blue and UV optoelectronic devices $[11,12]$. However, its most interesting application is connected with the quality of transparent and conductive oxide (TCO) [13]. This property

*E-mail: abdelmah@yahoo.com can be improved by a selective doping substituting $\mathrm{Zn}$ with higher valence elements such as $\mathrm{Al}, \mathrm{Ga}$ and $\mathrm{In}[14,15]$. This process could enable $\mathrm{ZnO}$ to achieve better electrical and optical properties for effective practical applications. A variety of physical and chemical methods have been used to prepare $\mathrm{ZnO}$ films presenting various morphologies. They include bars, tubes, flowers, rings, screws, discs, springs, nails, pencils and sheets [16-22], obtained by physical vapor deposition [23], thermal evaporation [24], sputtering [25], spray pyrolysis [26] and sol-gel [27]. Among all these methods sol-gel is an effective, easy and low-cost deposition technique making it possible to obtain nanostructured films. In the literature, many studies have been devoted to the influence of the low In doping concentration, where atomic ratio $\mathrm{x}$ of $\mathrm{In} /(\mathrm{In}+\mathrm{Zn})$ does not exceed $10 \%$ [28-31], however, high doping has rarely been studied because of the high price of indium [32].

The aim of this study was to investigate the effect of high indium doping, with an atomic ratio 
greater than $10 \%$, on the structural, morphological, optical and electrical properties of zinc oxide thin films obtained by dip-coating sol-gel method. The amount of consumed indium is after all very low compared to those used to obtain indium tin oxide (ITO).

\section{Experimental}

\subsection{Materials}

Zinc acetate dihydrate $\left(\mathrm{Zn}\left(\mathrm{CH}_{3} \mathrm{COO}\right)_{2} \cdot 2 \mathrm{H}_{2} \mathrm{O}\right.$, $98 \%$ purity), indium nitrate trihydrate $\left(\mathrm{In}\left(\mathrm{NO}_{3}\right)_{3} \cdot 3 \mathrm{H}_{2} \mathrm{O}, 99.9 \%\right.$ purity), absolute ethanol $\left(\mathrm{C}_{2} \mathrm{H}_{5} \mathrm{OH}, 99.8 \%\right.$ purity), and monoethanolamine $\left(\mathrm{NH}_{2} \mathrm{CH}_{2} \mathrm{CH}_{2} \mathrm{OH}, 99 \%\right.$ purity) purchased from Sigma-Aldrich, were used to prepare the highly In-doped $\mathrm{ZnO}$ thin films.

\subsection{Preparation of In-doped $\mathrm{ZnO}$ thin films}

Highly In-doped $\mathrm{ZnO}$ (IZO) thin films were prepared by sol-gel dip-coating method as reported in previous works $[33,34]$ using zinc acetate dihydrate and indium nitrate trihydrate as starting materials. These materials were dissolved in absolute ethanol to obtain a total molarity of 0.2. Monoethanolamine (MEA) was added to the mixture as a stabilizer. The molar ratio of MEA to zinc acetate was maintained at 1 . To obtain a clear and homogeneous solution, the mixture was stirred at $60{ }^{\circ} \mathrm{C}$ for $2 \mathrm{~h}$. The solution was usually prepared one day before using. The glass substrates were cleaned in an ultrasonic bath in acetone, ethanol and distilled water successively. The layers were deposited by immersing a substrate in the solution for $2 \mathrm{~min}$ (Dip-coater KSVDCX2), and then dried at high temperature of $300{ }^{\circ} \mathrm{C}$ for $4 \mathrm{~min}$ in an electric furnace (Nabertherm B-180). The procedure from immersing to drying was repeated 20 times, the films were then annealed at $500{ }^{\circ} \mathrm{C}$ for $2 \mathrm{~h}$. To investigate the effect of high In doping concentration on the physical properties of $\mathrm{ZnO}$, IZO thin films were fabricated at several In atomic ratios $(1 / 9,1 / 6$, and $1 / 3)$ corresponding, respectively, to 11 at.\%, 16 at.\% and 33 at.\% of indium. Therefore, the samples were referenced $\mathrm{ZO}$ for undoped $\mathrm{ZnO}$ and IZO11, IZO16 and IZO33 respectively for the In doped $\mathrm{ZnO}$.

\subsection{Analysis techniques}

The structural characterization of the films was performed using X-ray diffractometer (Bruker AXS-8D) with a CuK $\alpha$ radiation $(1.54056 \AA$ ), operating at $45 \mathrm{kV}$ and $40 \mathrm{~mA}$. The surface morphology was studied using A100 atomic force microscope of APE Research with Gwyddion 2.34 software. Optical properties were investigated using a spectrophotometer UV-Vis (Jasko V-630). Electrical characterization of the films was realized using the Hall measurement system (HMS-3000).

\section{Results and discussion}

\subsection{Structural properties}

The X-ray diffraction patterns of undoped $\mathrm{ZnO}$ and IZO films deposited on glass substrates with different indium atomic ratios are shown in Fig. 1. XRD analysis results are reported in Table 1. The diffraction peaks of all the samples were indexed to hexagonal wurtzite $\mathrm{ZnO}$, and no peak of other crystalline phase was detected despite the high concentration of indium introduced. The undoped $\mathrm{ZnO}$ films yield a sharp peak at $34.42^{\circ}$, which is attributed to ( $\left(\begin{array}{lll}0 & 0 & 2\end{array}\right)$ plane (JCPDS File No. 36-1451) [35], indicating a c-axis preferred orientation due to self-texturing phenomenon frequently observed in $\mathrm{ZnO}$ films [16, 17, 27]. Moreover, the $\left(\begin{array}{lll}0 & 0 & 2\end{array}\right)$ diffraction peak intensities of doped $\mathrm{ZnO}$ films decreased rapidly with increasing atomic ratio $\mathrm{x}$ and the amorphous background appeared. The mean crystallite size, calculated using Sherrer formula (equation 1), decreased with increasing In ratio (Table 1). All this indicates that an excess in indium doping ratio deteriorates the crystallinity of the films. Thambidurai et al. [36] reported similar results in their work devoted to IZO thin films (with $10.48 \%$ In) obtained by sol-gel technique. This behavior may be due to the difference in ionic radius between zinc $\left(\mathrm{Zn}^{2+}=0.74 \AA\right)$ and indium $\left(\mathrm{In}^{3+}=0.80 \AA\right)$ which reduces the incorporation of indium into $\mathrm{ZnO}$ matrix 
inducing a segregation of indium excess in the grain boundaries, which limits the lateral grain growth. Therefore, these conditions favor the growth of very fine crystallites oriented upwards. On the other hand, the peak (lllll $\left.\begin{array}{lll}0 & 2\end{array}\right)$ is slightly shifted towards small angles after indium doping. According to Bragg law (equation 2), this indicates an increase in the hexagonal lattice parameter $\mathrm{c}$ due to the expansion of the crystalline lattice (Table 1). A similar behavior has been reported and explained in detail by Lim et al. [29].

$$
\begin{aligned}
& D=0.9 \lambda / \beta_{002} \cdot \cos \left(\theta_{002}\right) \\
& 2 d_{002}=c=\lambda / \sin \left(\theta_{002}\right)
\end{aligned}
$$

$\mathrm{D}$ is the mean crystallites size, $\theta_{002}$ and $\beta_{002}$ are, respectively, the Bragg angle and the full width at half maximum (FWHM) of the $\left(\begin{array}{lll}0 & 0 & 2\end{array}\right)$ peak, $\lambda$ is the X-ray wavelength $(1.54056 \AA), \mathrm{d}_{002}$ is the $\mathrm{d}$-spacing between $\left(\begin{array}{lll}0 & 0 & 2\end{array}\right)$ crystalline planes and $\mathrm{c}$ is the hexagonal lattice parameter.

\subsection{Morphological properties}

Fig. 2 shows the AFM images of undoped $\mathrm{ZnO}$ and IZO thin films prepared by the sol-gel dip-coating method. For undoped $\mathrm{ZnO}$, rounded columns oriented upwards are observed in accord with the $\left(\begin{array}{lll}0 & 0 & 2\end{array}\right)$ preferred growth deduced from XRD analysis. Statistically, the average grain size is around $140 \mathrm{~nm}$ while the root mean square RMS roughness is $3.14 \mathrm{~nm}$ indicating a very smooth surface. However, for the doped $\mathrm{ZnO}$, the topography changed from a rounded columnar structure to a capillary structure. Lim et al. [29] observed by SEM a similar morphology in the form of nanowires (NWs) of hexagonal cross-sections typical of (l $\left.\begin{array}{lll}0 & 0\end{array}\right)$ oriented ZnO. Contrary to this, Nolan et al. [37], in the films containing a low content of indium (3 at.\%), observed different structures with large platelets.

The statistic calculations performed on the basis of AFM images using Gwyddion software indicate that the average grain size significantly decreases from $140 \mathrm{~nm}$ for undoped $\mathrm{ZnO}$ to $17.1 \mathrm{~nm}$ in IZO, when In atomic ratio increased. These results

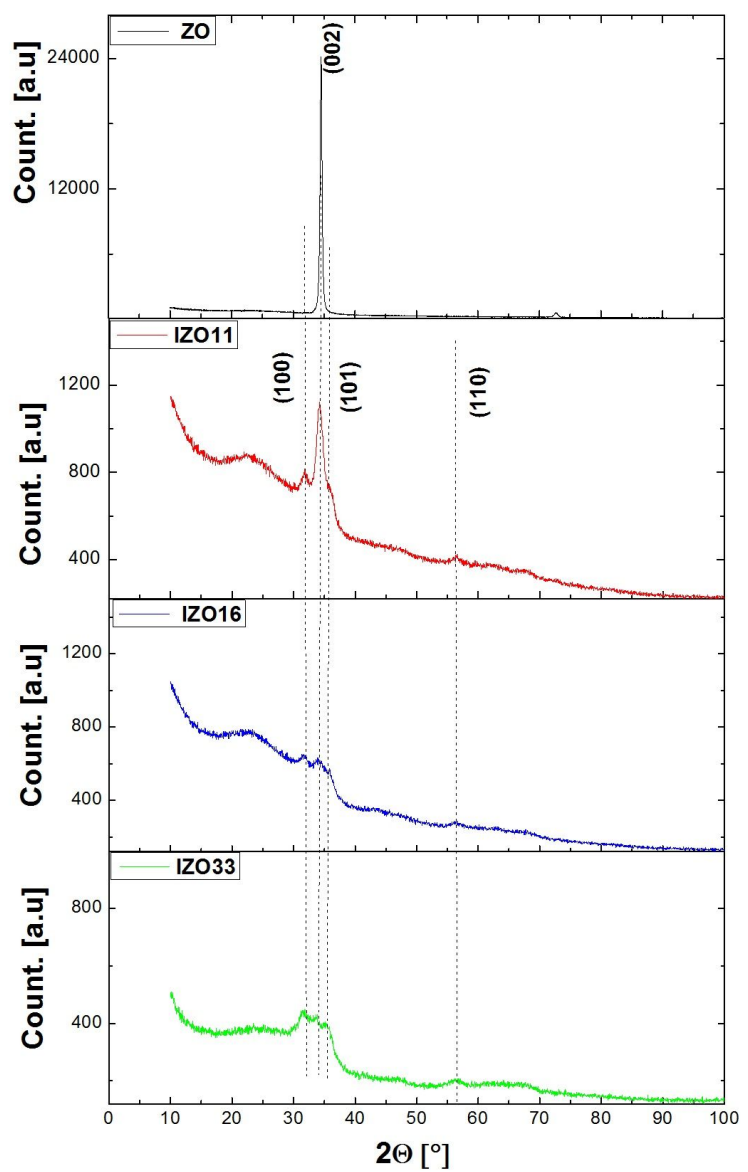

Fig. 1. XRD patterns of undoped $\mathrm{ZnO}$ and $\mathrm{IZO}$ thin films with different $\mathrm{In}$ atomic ratio $\mathrm{x}$.

agree with the fine crystallites revealed by the XRD analysis (Table 1). This behavior can be attributed to a competitive growth between amorphous indium oxide and $\mathrm{ZnO}$ crystalline phase, probably because of the high concentration of indium. The grain sizes and RMS roughness of all samples are listed in Table 2. As it can be seen, the RMS values decreased with increasing In atomic ratio, indicating an improvement in the surface quality.

\subsection{Optical properties}

Fig. 3a shows the optical transmission spectra of undoped $\mathrm{ZnO}$ and $\mathrm{IZO}$ thin films prepared with different In atomic ratios. In this figure, a very high transparency $(>93 \%)$ in the visible region is observed for IZO samples. The transmittance exceeds that of ITO, the absolute rival of the most 
Table 1. XRD patterns analysis: position, intensity and FWHM of $\left(\begin{array}{lll}0 & 0 & 2\end{array}\right)$ peak as well as the d-spacing, the hexagonal parameter $\mathrm{c}$ and the crystallites size $\mathrm{D}$.

\begin{tabular}{lcccccc}
\hline Samples & $2 \theta_{002}\left[{ }^{\circ}\right]$ & $\mathrm{I}_{002}[\mathrm{a} . \mathrm{u}]$ & $\beta_{002}\left[^{\circ}\right]$ & $\mathrm{d}_{002}[\AA]$ & $\mathrm{c}[\AA]$ & $\mathrm{D}[\mathrm{nm}]$ \\
\hline \hline ZO & 34.552 & 23780 & 0.360 & 2.593 & 5.187 & 23.1 \\
IZO11 & 34.202 & 398 & 1.034 & 2.619 & 5.238 & 9.3 \\
IZO16 & 33.982 & 102 & 1.887 & 2.642 & 5.285 & 5.1 \\
IZO33 & 33.775 & 45 & - & 2.660 & 5.321 & - \\
\hline
\end{tabular}

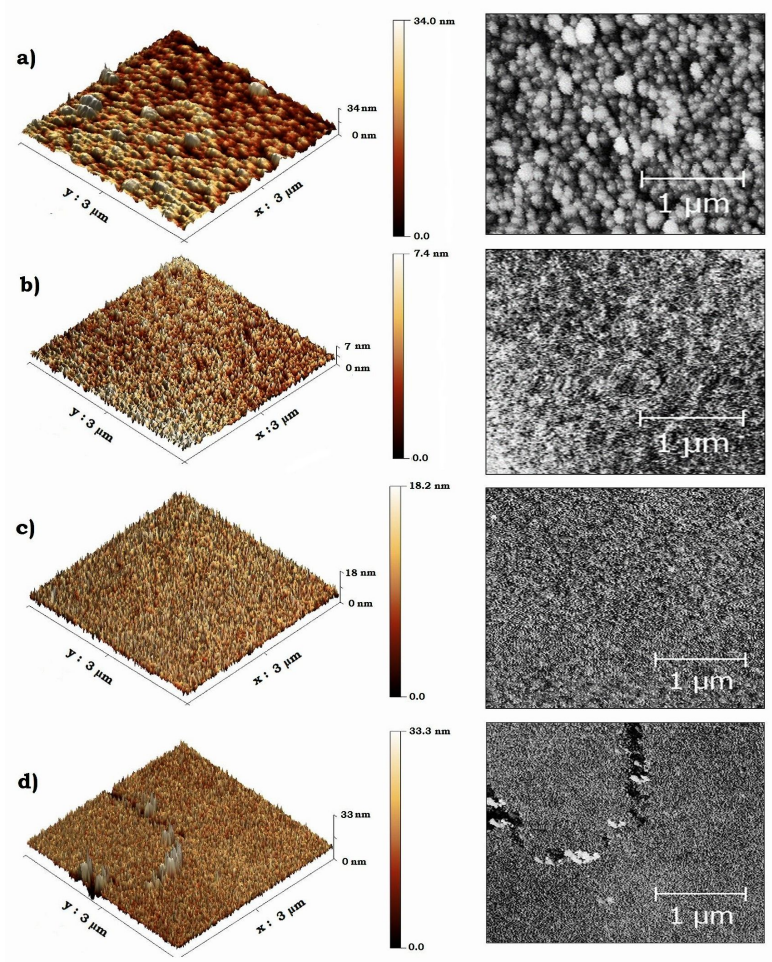

Fig. 2. AFM micrographs of (a) undoped $\mathrm{ZnO}$ and $\mathrm{IZO}$ thin films with different In atomic ratio $\mathrm{x}$, (b) 0.11 , (c) 0.16 and (d) 0.33 . The $3 \mathrm{D}$ and $2 \mathrm{D}$ images are shown in parallel.

commercial TCOs. Ramamoorthy et al. [38] found comparable behavior in their previous work. Contrary to these results, for low In doping concentration ( $<8$ wt.\%), Hafdallah et al. [28] reported a deterioration of the transparency with increasing indium concentration.

Therefore, it can be concluded that the high In doping has an important effect on the optical properties of IZO. The vertical growth of the zinc oxide (capillary structure acting as optical channels) facilitates the transmission of photons flow and minimizes the light scattering. This behavior could be very beneficial for optical or solar applications. The optical flow through the columnar $\mathrm{ZnO}$ thin films have been illustrated as in Fig. 4 .

In the transparent area of the spectra, interference fringes caused by multiple reflections on different interfaces are observed, which indicates that all deposited films are smooth and uniform [39]. The number of interference fringes increased following the introduction of indium, indicating an increase in the optical thickness. The thicknesses of the deposited films are reported in Table 1. They were obtained by fitting the transmittance experimental spectra with a theoretical model based on the Swanepoel formulation of the transmittance and the Forouhi-Bloomer description of optical indices [40, 41]. It is, therefore, noted (Fig. 3c) that the thickness increases with the In atomic ratio $\mathrm{x}$ despite the fact that the total molarity of all solutions was kept constant $(0.2 \mathrm{M})$. High indium doping leads to vertical growth of low-density films with larger thickness (the lateral growth limited by indium oxide). One can also evoke the expansion of the hexagonal structure of $\mathrm{ZnO}$ by the incorporation of indium atoms having an ionic radius greater than that of zinc. On another side, a shift of absorption edge towards lower energies with increasing atomic ratio $\mathrm{x}$ was observed, contrary to Lee et al. [32] who found in their studies that no significant shift was observed probably due to low In doping. This difference confirms the effect of the high level doping used in this work.

From the strong absorption area (around $400 \mathrm{~nm}$ ), the band gap energy of the films can be 

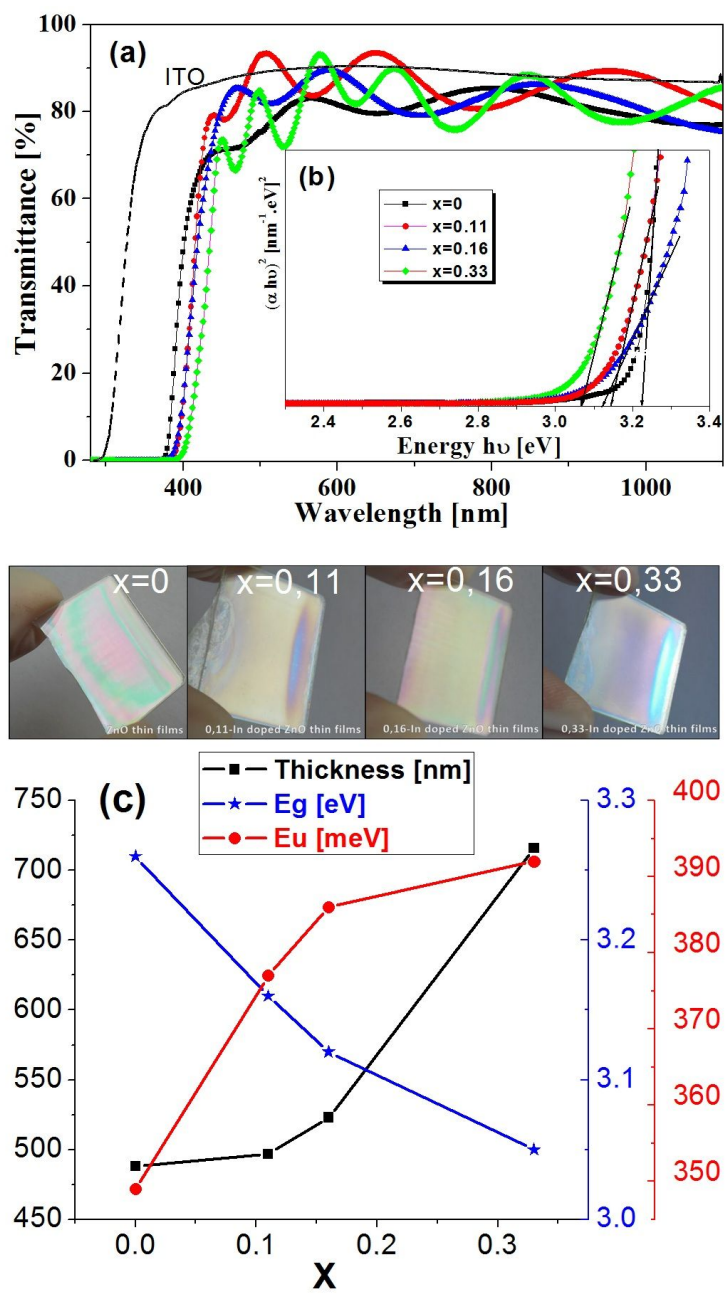

Fig. 3. (a) UV-Vis transmittance spectra, (b) Tauc plots and (c) thickness, band gap energy and Urbach energy of undoped $\mathrm{ZnO}$ and IZO thin films.

deduced from the linear part of $(\alpha h v)^{2}$ vs. hv Tauc plots shown in Fig. 3b. As a result, in case of direct gap materials, the absorption coefficient can be expressed as follows [42]:

$$
\alpha=A / h v \sqrt{h v-E_{g}}
$$

where: A is a constant, hv is the photon energy and $\mathrm{E}_{\mathrm{g}}$ is the optical band gap energy.

The values of the optical band gap energy for all the films are reported in Table 1. As it can be seen in Fig. 3c, the band gap energy decreases from $3.26 \mathrm{eV}$ for undoped $\mathrm{ZnO}$ to $3.05 \mathrm{eV}$ with increasing atomic ratio $\mathrm{x}$ in IZO films. These values are

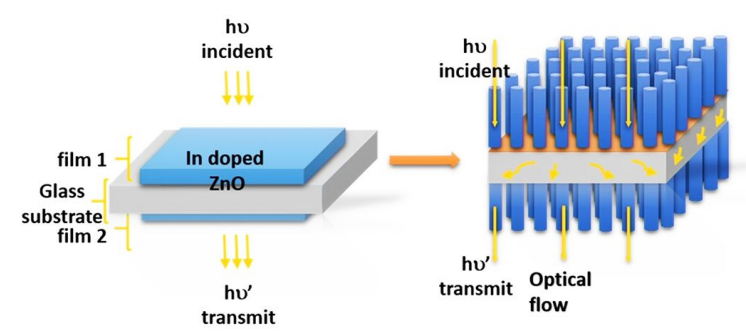

Fig. 4. Schematic view displaying the optical flow across the IZO thin films.

comparable to those found in the literature [28-31] and indicate that indium was correctly incorporated into the $\mathrm{ZnO}$ structure. The decrease of the band gap with the doping rate is mainly due to distortions in the crystal structure caused by the incorporation of doping impurities. This result is in agreement with the changes observed on the XRD patterns. Therefore, it can be inferred that the doping has occurred successfully.

Incorporation of impurities in a semiconductor often reveals the formation of a band tail in the limit of the band gap. In this region, the absorption coefficient is expressed by Urbach rule as [43]:

$$
\alpha=\alpha_{0} \exp \left(h v / E_{U}\right)
$$

where $\alpha_{0}$ is a constant and $E_{U}$ is the Urbach energy.

Urbach energy values, deduced from the transmittance spectra, are reported in Table 2. The increase of $\mathrm{E}_{\mathrm{U}}$ with increasing indium atomic ratio $x$ suggests that the structural disorder in IZO thin films increased. This behavior results from the increase in the concentration of the defects which leads to redistribution of the states, from the bands to the tails, allowing a greater number of possible transitions to the band tails, decreasing consequently the band gap energy [31, 44].

\subsection{Electrical properties}

To investigate the electrical properties of IZO thin films, their resistivity $\rho$, carrier concentration $\mathrm{n}$ and electrons mobility $\mu$ were deduced from Hall effect measurements recorded on all samples. These parameters are displayed in Fig. 5. First, the carrier concentration of electrons $n$ increased 
Table 2. AFM and transmittance analysis of IZO thin films.

\begin{tabular}{lcccccc}
\hline Samples & $\begin{array}{c}\text { Atomic ratio } \\
\mathrm{x}=\mathrm{In} / \mathrm{Zn}\end{array}$ & $\begin{array}{c}\text { Optical band } \\
\text { gap E }[\mathrm{eV}]\end{array}$ & $\begin{array}{c}\text { Urbach } \\
\text { energy } \\
\mathrm{E}_{\mathrm{U}}[\mathrm{meV}]\end{array}$ & $\begin{array}{c}\text { Film thickness } \\
\mathrm{d}[\mathrm{nm}]\end{array}$ & $\begin{array}{c}\text { Roughness } \\
\text { RMS } \\
{[\mathrm{nm}]}\end{array}$ & $\begin{array}{c}\text { Grain size } \\
\mathrm{D}[\mathrm{nm}]\end{array}$ \\
\hline \hline ZO & 0 & 3.26 & 349 & 488 & 3.1 & 140 \\
IZO11 & 0.11 & 3.16 & 377 & 497 & 1.6 & 33.1 \\
IZO16 & 0.16 & 3.12 & 386 & 523 & 1.2 & 20.6 \\
IZO33 & 0.33 & 3.05 & 392 & 716 & 1.1 & 17.1 \\
\hline
\end{tabular}

with increasing In atomic ratio, but it stayed almost constant with increasing In atomic ratio from 0.11 to 0.33 . This signifies that the solid solubility of indium in $\mathrm{ZnO}$ was reached. Contrary to electron concentration, the mobility decreased with increasing In atomic ratio, in agreement with the growing disorder deduced from Urbach energy analysis, the combination of these two effects in Ohm law gave a minimum resistivity of $0.41 \Omega \cdot \mathrm{cm}$ at $11 \%$ In concentration. However, an increase in In atomic ratio from 0.11 to 0.33 led to an increase the resistivity.

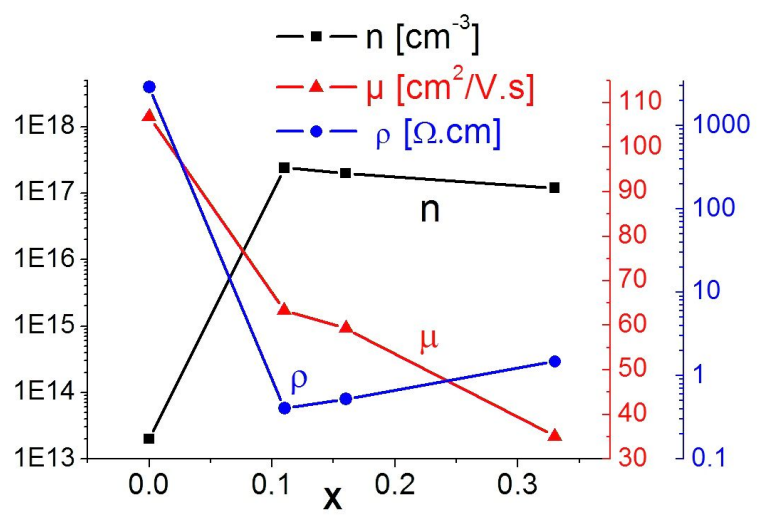

Fig. 5. Resistivity $\rho$, carrier concentration $n$ and mobility $\mu$ of IZO thin films with different In atomic ratio $\mathrm{x}$.

According to previous studies [45, 46], it is commonly accepted that electrons are generated by ionization of interstitial zinc atoms and oxygen vacancies in undoped $\mathrm{ZnO}$ to which an excess of electrons is added by the trivalent doping atoms substituting $\mathrm{Zn}$ [47]. Besides, similar results $[30,31]$ show that the excess of indium is segregated in grain boundaries, where these atoms become electrically inactive, and hinder the mobility of electrons, increasing the resistivity of IZO films [47]. When comparing the resistivity reported here to similar works, it is lower than $0.84 \Omega \cdot \mathrm{cm}$ obtained by Benhaliliba et al. [48] however Lim et al. [29] measured a resistivity of $0.06 \Omega \cdot \mathrm{cm}$ along a nanowire of $1.03 \mu \mathrm{m}$ length. The resistivity measured in our case is lateral therefore takes into account the effect of grain boundaries.

\section{Conclusions}

In this work, heavily indium doped $\mathrm{ZnO}$ thin films have been prepared by the sol-gel dip-coating method using zinc acetate and indium nitrate as precursors. The effect of high In doping on the physical properties of $\mathrm{ZnO}$ was studied in details. XRD results indicated that the crystallinity was much deteriorated with increasing In atomic ratio $\mathrm{x}$. This stress was due to the difference between ion radius of zinc and indium as well as the high level of doping generating indium segregation at the grain boundaries which hindered the lateral growth of the crystallites. The AFM investigation indicated that all IZO samples present capillary structures, leading to improving the photons flow through the films, which explains the very high recorded transmittance. Among all synthesized samples, $11 \%$ In doped $\mathrm{ZnO}$ have the highest transmittance $(93.5 \%)$ and the lowest resistivity $(0.41 \Omega \cdot \mathrm{cm})$ which results in the best TCO properties.

\section{Acknowledgements}

Laboratoire des Composants Actifs et Matériaux (LCAM), Université Larbi Ben M'Hidi, Oum el Bouaghi 04000, Algieria, has supported this work. The authors are grateful to the Algerian MESRS (Ministère 
Table 3. Electrical analysis of IZO thin films.

\begin{tabular}{ccccc}
\hline Samples & $\begin{array}{c}\text { Atomic ratio } \\
\mathrm{x}=\mathrm{In} / \mathrm{Zn}\end{array}$ & $\begin{array}{c}\text { Carrier concentration } \\
{\left[\mathrm{cm}^{-3}\right]}\end{array}$ & $\begin{array}{c}\text { Mobility } \mu \\
{\left[\mathrm{cm}^{2} / \mathrm{V} \cdot \mathrm{s}\right]}\end{array}$ & $\begin{array}{c}\text { Resistivity } \rho \\
{[\Omega \cdot \mathrm{cm}]}\end{array}$ \\
\hline \hline ZO & 0 & $2.0 \times 10^{13}$ & 106.9 & $2.9 \times 10^{3}$ \\
IZO11 & 0.11 & $2.4 \times 10^{17}$ & 63.3 & 0.41 \\
IZO16 & 0.16 & $2.0 \times 10^{17}$ & 59.3 & 0.53 \\
IZO33 & 0.33 & $1.2 \times 10^{17}$ & 35.1 & 1.48 \\
\hline
\end{tabular}

de L'Enseignement Supérieur et de la Recherche Scientifique) for the financial support. S. Benzitouni thanks particularly M. Toubane (Research Unit of Materials, Processes and Environment, URMPE-Boumerdes-Algérie) for XRD measurements.

\section{References}

[1] LIM J.H., KANG C.K., KIM K.K., PARK I.K., HWANG D.K., PARK S.J., Adv. Mater., 18 (2006), 2720.

[2] Park Y.J., Song H., Ko K.B., Ryu B.D., CuOng T.V., Hong C.H., J. Nanomater., 2016 (2016), ID 7947623 (6).

[3] Djessas K., Bouchama I., Gauffier J.L., BeNAYADI Z., Thin Solid Films, 555 (2014), 28.

[4] SyU Y.K., Tingare Y., Lin S.Y., YeH C.Y., WU J.J., Molecules, 21 (2016), 1025.

[5] Dilonardo E., Penza M., Alvisi M., Difranco C., Palmisano F., Torsi L., Cioffi N., Beilstein J. Nanotechnol., 7 (2016), 22.

[6] Saidani T., ZaAbat M., Aida M.S., Boudine B., Superlattice. Microst., 88 (2015), 315.

[7] Dobrucka R., DŁugaszewska J., Saudi J. Biol. Sci., 23 (2016), 517.

[8] Cadafal CH., Gazquez G., Lei S., George A., Gullapalli H., Boukamp B.A., AJayan P.M., TEN Elshof J.E., ACS Appl. Mater. Interfaces, 21 (2016), 13466.

[9] Liu J., Fernandez-Serra M.V., Allen P.A., Phys. Rev. B, 93 (2016), 081205(R).

[10] WANG Z.L., MRS Bull., 37 (2012), 814.

[11] Boruah B.D., Misra A., ACS Appl. Mater. Interfaces, 8 (2016), 18182.

[12] Jin Z., Zhou Q., Chen Y., Mao P., Li H., LiU H., Wang J., Yuliang L., Adv. Mater., 28 (2016), 3697.

[13] LiU H., Avrutin V., Izyumskaya N., ÖZgür Ü., Morkoç H., Superlattice. Microst., 48 (2010), 458.

[14] Jun M.C., PARK S.U., KoH J.H., Nanoscale Res. Lett., 7 (2012), 639.

[15] Minami T., Sato H., Nanto H., Takata S., Jpn. J. Appl. Phys., 24 (1985), L781.

[16] Liu C., Masuda Y., Wu Y, Takai O., Thin Solid Films, 503 (2006), 110.

[17] YANG J.H., Zheng J.H., ZhaI H.J., YANG L.L., LiU L., Gao M., Cryst. Res. Technol., 44 (2009), 619.

[18] Kou H., Jia L., Wang C., Carbon, 50 (2012), 3522.

[19] Wu X., Qu F., Zhang X., Cai W., Shen G., J. Alloy. Compd., 486 (2009), 13.
[20] Li F., Ding Y., Gao P., Xin X., Wang Z.L., Angew. Chem. Int. Ed., 43 (2004), 5238.

[21] Shen G.Z., BAndo Y., LiU B.D., Golberg D., LeE C.J., Adv. Funct. Mater., 16 (2006), 410.

[22] Feng X.Y., Wang Z., Zhang C.W., Wang P.J., Physica E, 54 (2013), 144

[23] Waugh M.R., Hyett G., Parkin I.P., Chem. Vap. Depos., 14 (2008), 366.

[24] Umar A., Karunagaran B., Suh E.K., Hahn Y.B., Nanotechnology, 17 (2006), 4072.

[25] Park T.E., Kim D.C., Kong B.H., Cho H.K., J. Korean Phys. Soc., 45 (2004), S0697.

[26] Lehraki N., Aida M.S., Abed S., Attaf N., Poulain M., Curr. Appl. Phys., 12 (2012), 1283.

[27] Bao D., Gu H., KuAng A., Thin Solid Films, 312 (1998), 37.

[28] Hafdallah A., Yanineb F., Aida M.S., Attaf N., J. Alloy. Compd., 509 (2011), 7267.

[29] Lim S.Y., BRAhMA S., LiU C.P., WANG R.C., HuAng J.L., Thin Solid Films, 549 (2013), 165.

[30] Chen K.J., Hung F.Y., Chang S.J., Hu Z.S., Appl. Surf. Sci., 255 (2009), 6308.

[31] Caglar M., Ilican S., Caglar Y., Thin Solid Films, 517 (2009), 5023.

[32] LEE S.Y., PARK B.O., Thin Solid Films, 484 (2005), 184.

[33] Saidani T., ZaAbat M., Aida M.S., Barille R., Almohamed Y., J. Mater. Electron., 28 (2017), 9252.

[34] Saidani T., ZaAbat M., Aida M.S., Benaboud A., Benzitouni S., Boudine A., Superlattice. Microst., 75 (2014), 47.

[35] Powder Diffraction File Data Card 5-644, 3cPDS International Center for Diffraction Data, Swartmore, PA.

[36] Thambidurai M., KIM J.Y., Kang C.M., Muthukumarasamy N., Song H.J., Song J., Ko Y, Velauthapillai D., Lee C., Renew. Energy, 66 (2014), 433.

[37] Nolan M.G., Hamilton J.A., Brien S.O, Bruno G., Pereirad L., Fortunatod E., $J$. Photochem. Photobiol. A Chem., 219 (2011), 10.

[38] Ramamoorthy K., Kumar K., ChandramoHAN R., SANKARANARAYANANA K., SARAVANAN R., KityK I.V., RAMASAMY P., Opt. Commun., 262 (2006), 91.

[39] Kaur G., Mitra A., YadaV K.L., Mater. Int., 25 (2015), 12

[40] Hoggas K., Nouveau C., Djelloul A., BououdINA M., Appl. Phys. A, 120 (2015), 745. 
[41] Forouhi A.R., Bloomer I., Phys. Rev. B, 34 (1986), 7018.

[42] Pankove J.I., Optical Processes in Semiconductors, Prentice Hall Inc., Englewood Cliffs, New Jersey, 1971.

[43] TAUC J., Amorphous and Liquid Semiconductors, Plenum Press, New York, 1974.

[44] O'Leary S.K., Zukotynski S., Perz J.M., J. NonCryst. Solids, 210 (1997), 249.

[45] Park Y. R., Kim E. K., Jung D., PARK T. S., Kim Y.S., Appl. Surf. Sci., 254 (2008), 2250.

[46] Chen K.J., FAng T.H., Hung F.Y., Ji L.W., Chang S.J., Young S.J., Hsiao Y.J., Appl. Surf. Sci., 254 (2008), 5791.
[47] Benouis C.E., Benhaliliba M., Juarez A.S., Aida M.S., Chamid F., YaKuphanoglue F., $J$. $A l$ loy. Compd., 490 (2010), 62.

[48] Benhaliliba M., Benouis C.E., Mouffak Z., Ocak Y.S., Tiburci O., Silver A., Aida M.S., Garcia A.A., Tavira A., Sanchez Juarez A., $\mathrm{Su}$ perlattice. Microst., 63 (2013), 228.

Received 2017-06-27

Accepted 2018-03-24 